\title{
Analysis of Interventional Radiology Publications Regarding COVID-19
}

To date, over 7.27 million confirmed cases of COVID-19 have been diagnosed worldwide. In the face of this pandemic, all physicians must be up to date with the recent literature to practice evidence-based medicine. In this letter, we have reviewed the publication trends of COVID-19-related articles in the interventional radiology (IR) literature and have determined the country of origin of the publication for PubMed indexed articles till June 12, 2020.

We conducted a literature search in PubMed for the journal entries concerning COVID-19 and Interventional Radiology. The search terms we used for our search are COVID 19, severe acute respiratory syndrome coronavirus 2, 2019 nCoV, SARS CoV 2, Wuhan coronavirus, radiology, interventional, interventional radiology. A total of 111 articles were found by using the above search terms, after removing duplicates, reviewing titles and abstracts, and screening full texts, 36 articles were finally selected for the analysis [Figure 1]. The country of origin for the articles $(n=36)$ was also identified with the help of the address provided for the corresponding authors.

The 36 publications selected for the analysis were placed into seven broad categories. Figure 2 shows the different topics along with their percentage distribution. "Practice guidelines" represented about $47 \%(n=17 / 36)$ of the available articles. Other topics of publication included, Editorials $(14 \% ; n=5 / 36)$, Stroke $(14 \% ; n=5 / 36)$, Use of IR in COVID-19 management ( $8 \% ; n=3 / 36)$, Training $(6 \% ; n=2 / 36)$, Pulmonary embolism management $(6 \% ; n=2 / 36)$, and Management of Bleeding in COVID-19 patients $(6 \% ; n=2 / 36)$. The country of origin analysis showed a majority of the publications originated from the United States $(31 \% ; n=11 / 36)$ followed by Italy $(14 \% ; n=5 / 35)$, China and Singapore $(11 \% ; n=4 / 36)$, Spain and Switzerland $(8 \% ; n=3 / 36)$, France and Canada $(6 \% ; n=2 / 36)$, and United Kingdom and Austria $(3 \% ; n=1 / 36)$ [Figure 3].

The scientific literature represents the accumulated experience, new advances in knowledge, and new information in the form of original scientific articles. In our search, we found that most of the articles published regarding COVID-19 in IR were practice guidelines given by different IR societies and practice groups, these guidelines are especially critical in this pandemic as they can serve as a blueprint for specific institutional guidelines to organize IR services and provide effective care ${ }^{[1]}$ Various editorials have also been published by journal editors and invited authors that share their departments' unique perspectives, which will be helpful for the readers.

Different publications on stroke included changes in mechanical thrombectomy outcomes due to the pandemic

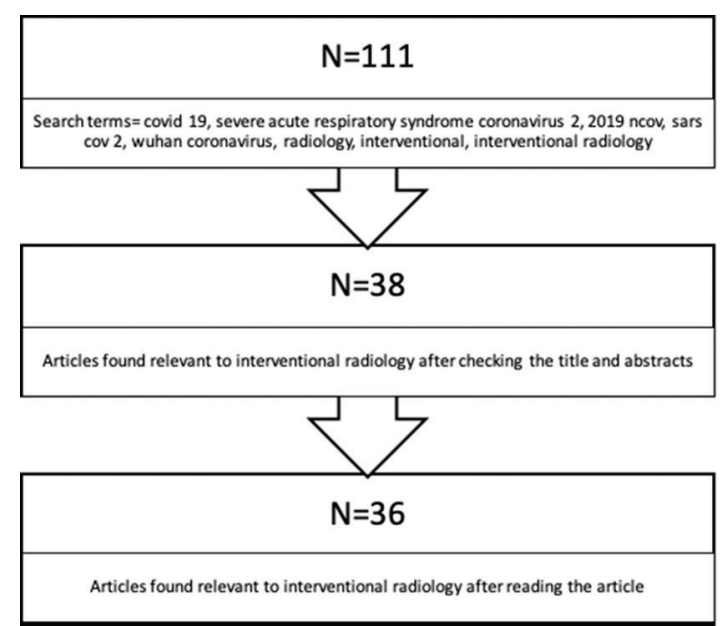

Figure 1: Literature search methodology

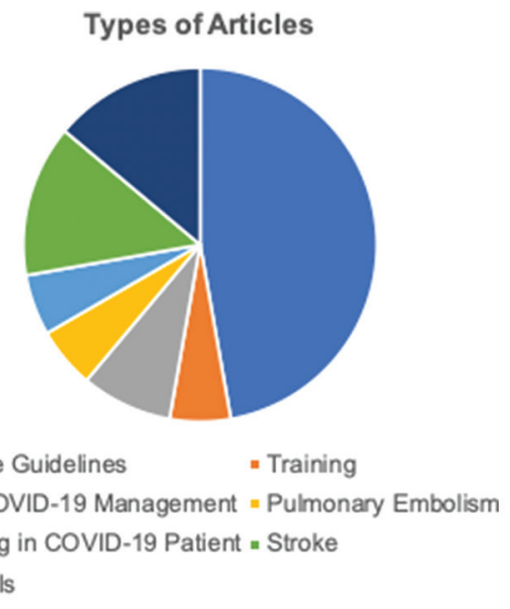

Figure 2: Types of articles published in interventional radiology literature regarding COVID-19

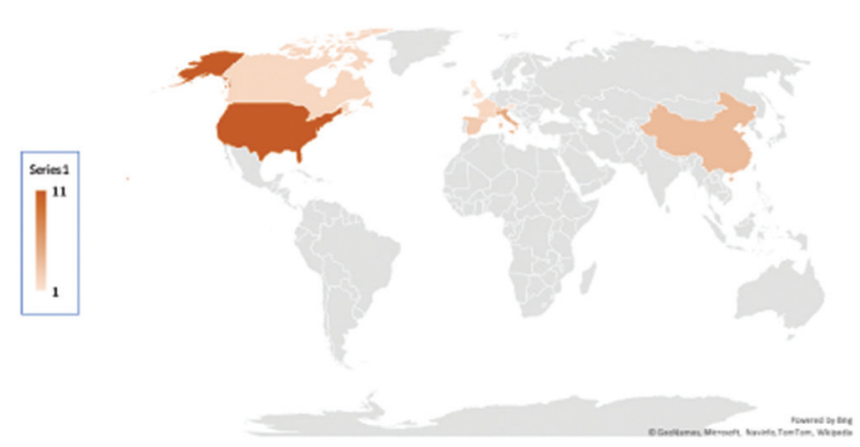

Figure 3: The world map, highlighting the countries which contributed to interventional radiology publications regarding COVID-19

guidelines for effective management of stroke patients to prevent delays and a framework for setting up remote consent approval..$^{[2]}$ The rate of venous thromboembolism, 
causing pulmonary embolism in COVID-19 patients, has increased as the standard treatment with anticoagulation is ineffective and particularly dangerous in some cases. $^{[3]}$ Therefore, these patients should be management by interventional radiologists, who can perform minimally invasive percutaneous pulmonary thrombectomy in collaboration with hematologists and critical care physicians. ${ }^{[4]}$

This pandemic has also affected the medical education of IR trainees in unprecedented ways. During this time, it is essential to re-evaluate trainee expectations and duties to help them achieve their clinical and educational goals while maintaining their safety. ${ }^{[5]}$

Most publications have originated from the United States, followed by various European countries, China, and Singapore. The absence of publications for South-East Asian countries could indicate the difference in the research environment in those countries due to heavy clinical duties and scarcity of time and resources for research.

In this brief letter, our analysis has revealed the characteristics and trends of current IR COVID-19 publications, which may provide helpful information to clinicians, researches, and the editorial staff of various journals.

Financial support and sponsorship

Nil.

\section{Conflicts of interest}

There are no conflicts of interest.

\section{Tushar Garg, Apurva Shrigiriwar}

Department of Interventional Radiology, Seth GS Medical College and KEM Hospital, Mumbai, Maharashtra, India

Address for correspondence: Mr. Tushar Garg,

Department of Interventional Radiology, Seth GS Medical College and KEM Hospital, Acharya Donde Marg, Mumbai - 400 012, Maharashtra,

India.

E-mail: gargtushark@outlook.com

\section{References}

1. Gogna A, Punamiya S, Gopinathan A, Irani F, Toh LHW, Wen Cheong LH, et al. Preparing IR for COVID-19: The Singapore experience. J Vasc Interv Radiol 2020;31:869-75.

2. Kerleroux B, Fabacher T, Bricout N, Moïse M, Testud B, Vingadassalom $\mathrm{S}$, et al. Mechanical thrombectomy for acute ischemic stroke amid the COVID-19 outbreak: Decreased activity, and increased care delays. Stroke 2020;51:2012-7.

3. Bargellini I, Cervelli R, Lunardi A, Scandiffio R, Daviddi F, Giorgi L, et al. Spontaneous bleedings in COVID-19 patients: An emerging complication. Cardiovasc Intervent Radiol 2020;43:1095-6.

4. Qanadli SD, Gudmundsson L, Rotzinger DC. Catheter-directed thrombolysis in COVID-19 pneumonia with acute PE: Thinking beyond the guidelines. Thromb Res 2020;192:9-11.

5. Warhadpande S, Khaja MS, Sabri SS. The impact of COVID-19 on interventional radiology training programs: What you need to know. Acad Radiol 2020;27:868-71.

This is an open access journal, and articles are distributed under the terms of the Creative Commons Attribution-NonCommercial-ShareAlike 4.0 License, which allows others to remix, tweak, and build upon the work non-commercially, as long as appropriate credit is given and the new creations are licensed under the identical terms.

\begin{tabular}{|l|l|}
\multicolumn{2}{|c|}{ Access this article online } \\
\hline Quick Response Code: & Website: \\
& www.arabjir.com \\
\cline { 2 - 2 } & DOI: \\
\hline
\end{tabular}

How to cite this article: Garg T, Shrigiriwar A. Analysis of interventional radiology publications regarding COVID-19. Arab J Intervent Radiol 2020;4:136-7.

Received: 01-07-2020, Accepted: 09-07-2020,

Online Published: 10-08-2020.

(C) 2020 The Arab Journal of Interventional Radiology | Published by Wolters Kluwer - Medknow 